\title{
Why Do Drug Prescribing Rates Differ Across Irish Regions?
}

\author{
Martin Kenneally and Brenda Lynch*
}

Centre for Policy Studies, University College Cork, Cork, Ireland

\begin{abstract}
In Ireland $68.3 \mathrm{~m}$ drug items were prescribed in 2010, a national average prescribing rate (APR) of 14.9 items per person. Regional APRs ranged from 13.2 items in the East to 17.1 items in the South-East region.

We construct a model of regional prescribing rates in Ireland that embeds the effects of the national prescribing rates under each of Ireland's three main community drug schemes, the regional coverage rates of those schemes and each region's health status. Drawing on the CPS Composite Health Index to measure regional health status and the Primary Care Reimbursement Service database for all other variable, we estimate the model by Ordinary Least Squares (OLS).

We find that variations in regional prescribing rates were mainly due to the different regional coverage rates of Ireland's community drug schemes, especially its GMS (General Medical Services) community drug scheme and, to a lesser extent, to differences in each region's health status.

We simulate the estimated model and find that a percentage point reduction in each region's GMS coverage rate would reduce the number of items prescribed nationally twice as much as a percentage point gain in each region's health status.

We find that regional prescribing rates respond most to changes in national prescribing rates in low-income regions that have high GMS coverage rates and poor health status. At the height of Ireland's public debt crisis in 2010 , government policy pressured GMS national prescribing rates down by around $2 \%$ in an effort to contain public drug costs. That reduced regional prescribing rates most in low-income regions that had high GMS coverage rates and poor health status.
\end{abstract}

Keywords: Prescribing rates; Ireland

\section{Introduction}

The Irish Government reduced its total net current spending by $14 \%$ between 2008 and 2010, following the onset of recession in 2008 , its public debt and banking crises and to comply with the terms of its emergent 2010 IMF / OECD / ECB bailout. Reducing public noncapital public spending proved difficult, [1] especially public health spending of $€ 13.2 \mathrm{bn}$ in 2008. Recent System of Health Accounts data [2] indicate Ireland's current total health spending was still $€ 18$.4bn or $12.4 \%$ of gross national income in 2013. Current public health spending was $€ 13.08 \mathrm{bn}$ in 2013 , around $71 \%$ of all current health spending, the remaining $29 \%$ being funded by private insurance and out of pocket.

The Health Services Executive (HSE) provides all of Ireland's public health services in hospitals and across communities. Government reduced its total budget by $€ 3.3$ bn (22\%) between 2008 and 2013 [3].

Pharmaceutical spending topped $€ 180$ billion in the EU in 2008 and accounted for $17 \%$ of total health spending [4] in the EU and Ireland. In 2009 Ireland was the fourth highest pharmaceutical spender per capita in the OECD [5] (after the US, Canada and Greece); its per capita spend on pharmaceuticals peaked at €501.48 [6] in 2010.

Reducing the $€ 2.4 \mathrm{bn}$ government spent on Primary Care (Medical Card Services) drugs in 2008 [6] has proven especially difficult. These drugs are dispensed under three main primary care community drug schemes. We ignore minor schemes, the largest of which was the secondary care High Tech Drugs (HTD) scheme, which covered 55,000 of the $4.5 \mathrm{~m}$ population in 2010 and dispensed hospitaloriginated prescriptions, mainly anti-rejection and cancer drugs, to eligible persons. The GMS (General Medical Services) is Ireland's main and most costly primary care community drug scheme. It is meanstested, covered $35 \%$ of the 2010 population and dispensed drugs at a nominal charge of $€ 0.50$ per item, subject to a maximum of $€ 10$ per family per month: the actual full annual public cost of GMS drugs, per person covered, was $€ 763.25$ in 2010 [7]. Persons with incomes above the qualifying threshold but who have exceptional medical need may qualify, if withholding GMS cover would impose "undue hardship". The GMS scheme is also, and by far, Ireland's most prescriptionintensive community drug scheme. The LTI (Long-Term Illness) primary care scheme is not means-tested. It covered just the $3 \%$ of the 2010 population diagnosed with one or more of 18 scheduled long term illnesses (e.g. epilepsy and diabetes) to whom it dispensed drugs free of charge. The DP (Drugs Payment) primary care scheme is not means-tested and covers everyone else. It covered the $61 \%$ of the 2010 population that was ineligible for the other two schemes. Persons or families with DP cover in 2010 paid up to a maximum of $€ 120$ for each month's prescriptions; the State paid any monthly excess arising. See Barry, Malloy D, Usher C, and L. Tilson[8] for a fuller account of Ireland's community drug schemes.

The HSE negotiated substantial reductions in the unit cost of all community drugs between 2008 and 2010 but recession so swelled the means-tested GMS-covered population that the number of community

*Corresponding author: Brenda Lynch, Centre for Policy Studies, University College Cork, Ireland, Tel: (+353) 214-902-636; Fax: (+353) 214-902-636; E-mail: brendalynch@ucc.ie

Received September 19, 2015; Accepted March 08, 2016; Published March 15 2016

Citation: Kenneally M, Lynch B (2016) Why Do Drug Prescribing Rates Differ Across Irish Regions? Pharmacoeconomics 1: 106.

Copyright: (c) 2016 Kenneally M, et al. This is an open-access article distributed under the terms of the Creative Commons Attribution License, which permits unrestricted use, distribution, and reproduction in any medium, provided the original author and source are credited. 
drug items prescribed increased and eroded the negotiated cost savings[9].

Ireland was divided into 8 HSE regions in 2010: Table 1 gives their population shares and maps their county membership. A total of $68.3 \mathrm{~m}$ community drug items were prescribed in Ireland in 2010, an average prescribing rate (APR) of 14.87 items per person in Ireland: regional APRs ranged from 13.17 items in the East region to 17.09 items in the South-East region (Table 2) and displayed the considerable regional variation shown in Figure 1. The Dublin-centred East region had 36\% of the Irish population, incomes $5 \%$ above the national average, a low elderly population share $(10 \%)$ and the best health status of any region (6\% above the national average). The North-West had the highest elderly population share (13\%) and but despite having similar income to the Midlands it had a noticeably better health status and a lower prescribing rate than it.

The objective of this paper is to explain why regional APRs differ or, equivalently, why the average size of drug baskets (scaled by population) differs across regions.

We show how each region's community drug scheme coverage rates, its mapped epidemiological health profile and national prescribing rate norms jointly determine its regional prescribing rate or APR. To date, these regional prescribing differences have attracted little research attention.

\section{Methods}

In 201024 therapeutic main groups of medicines accounted for $80 \%$ of the $68.3 \mathrm{~m}$ community drug items prescribed in Ireland under the community drug schemes, as detailed in Table 3 . We extracted the national prescribing rates (items / population) for each of these 24 groups from the Primary Care Reimbursement Service (PCRS) database. We aggregated the 24 national prescribing rates into 6 main WHO / ATC health categories - (i) Alimentary Tract and Metabolism (ii) Cardiovascular system (iii) Nervous system (iv) Respiratory system (v) Various and (vi) Other (i.e. the remaining 9 'official' ATC groups combined. See WHO [10] for ATC categories and methodological details.
Health indicators quantify key dimensions of health: composite indicators combine different single indicators. The CPS Composite Health Index measures the comparative prevalence in each of the 8 Irish regions in 2010 of the health conditions for which each of the 6 ATC categories of drugs were prescribed. See Kenneally and Lynch [11] for a detailed account.

We constructed expected prescribing rates(EPRs) for each of the 6 ATC drug categories in each region by first adjusting the national prescribing rate for each ATC category of drugs pro ratawith its CPS regional health index value. For example, the Midlands CPS Cardiovascular Health Index of 115 in 2010 indicates that prescriptionweighted cardiovascular health conditions were, on average, $15 \%$ more prevalent in the Midlands than nationally, i.e., $I_{C}^{M I D}=1.15$. The GMS national prescribing rate (NPR) for cardiovascular items was 8 items per GMS person covered (i.e., $N P R_{c}^{G M S} \approx 8$ ) in 2010 . Thus, the expected GMS prescribing rate in the Midlands $\left(E P R_{c}^{G M S, M I D}\right)$ for cardiovascular items was 9.31; that is, $E P R_{c}^{G M S, M I D}=N P R_{c}^{G M S} * I_{C}^{M I D L A N D S}=8 * 1.15=9.31$.

We similarly constructed GMS EPRs for the other 5 ATC health categories and then summed over all 6 ATC categories to yield the total Midlands EPR for its GMS population. In essence, EPRs simply adjust the national prescribing norms for each health condition and community drug scheme in line with each region's health index status for that condition.

However, national prescribing rates or norms differ sharply across the three community drug schemes. For example, 8 cardiac items were prescribed nationally per GMS-eligible person in 2010 but just 1 was prescribed nationally per DP-eligible person (i.e., $N P R_{c}^{D P} \approx 1$ ). Persons who are ineligible for the GMS and LTI schemes are automatically eligible for the DP scheme. Some DP prescription costs fall below the DP monthly claims threshold and are not claimed. This imparts a slight downward bias to total DP prescribing rates but not to publicly subvented rates.

These large differences in scheme prescribing norms obliged us to construct separate cardiac EPRs for the DP and LTI drug schemes in the Midlands. We repeated the exercise for the remaining 7 regions

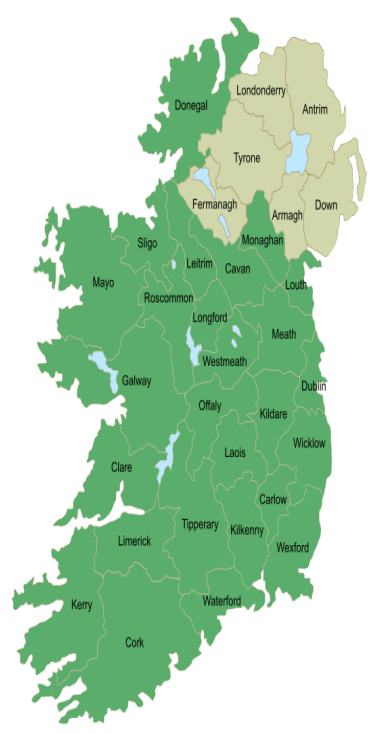

\begin{tabular}{|c|r|c|}
\hline Regions & Counties & Population Shares 2010 \\
\hline 1. East & Dublin, Kildare, Wicklow & $35.72 \%$ \\
\hline 2. Midlands & Laois, Offaly, Longford and Westmeath & $6.04 \%$ \\
\hline 3. Mid-West & Clare, Limerick and North Tipperary & $8.33 \%$ \\
\hline 4. North East & Cavan, Louth, Meath and Monaghan & $9.34 \%$ \\
\hline 5. North West & Donegal, Leitrim and Sligo \\
\hline 6. South East & Carlow, Kilkenny, South Tipperary Waterford and Wexford & $5.58 \%$ \\
\hline 7. South West & Cork and Kerry & $10.88 \%$ \\
\hline 8. West & Galway, Mayo and Roscommon & $14.4 \%$ \\
\hline IRELAND & & $9.7 \%$ \\
\hline
\end{tabular}

Sources. Population - Central Statistics Office

Table 1: HSE regions, county memberships and population shares in 2010. 


\begin{tabular}{|c|c|c|c|c|c|c|}
\hline & Population & $\begin{array}{l}\text { GMS + LTI + DP } \\
\text { Community Drug } \\
\text { Items }\end{array}$ & $\begin{array}{c}\text { GMS + LTI + DP } \\
\text { Regional Prescribing } \\
\text { Rates }\end{array}$ & $\begin{array}{c}\text { Health Index } \\
\text { Numbers Ireland = } \\
100\end{array}$ & $\begin{array}{c}\text { Disposable Income } \\
€ ' 000 \text { pa. [Index } \\
\text { Numbers] }\end{array}$ & $\begin{array}{c}\text { Population } \\
\text { Percentage aged 65+ }\end{array}$ \\
\hline East & $1,640,321$ & $21,597,381$ & 13.17 & 106.14 & 20.3 [105] & 10 \\
\hline Midlands & 277,449 & $4,560,185$ & 16.44 & 91.89 & $17.1[88.6]$ & 11 \\
\hline Mid-West & 382,712 & $6,151,829$ & 16.07 & 103.92 & 19.1 [99] & 11.8 \\
\hline North East & 429,002 & $5,996,451$ & 13.98 & 102.31 & $17.3[89.6)$ & 10 \\
\hline North West & 256,154 & $3,986,284$ & 15.56 & 94.04 & $17.3[89.6]$ & 13 \\
\hline South East & 499,655 & $8,541,380$ & 17.09 & 97.05 & $18.1[93.8]$ & 12 \\
\hline Southern & 661,398 & $10,679,471$ & 16.15 & 100.48 & 19.2 [99.5] & 12 \\
\hline Western & 445,262 & $6,789,882$ & 15.25 & 96.52 & 18.5 [95.85] & 12.3 \\
\hline Ireland & $4,591,953$ & $68,302,863$ & 14.87 & 100 & $19.3(100)$ & 11.1 \\
\hline
\end{tabular}

Sources. Population - Central Statistics Office. Prescribed Items - Primary Care Reimbursement Service Database. Health - CPS Composite Health Index. Incomes CSO. County Income Series.

Table 2: Regional prescribing rates, incomes, health status and elderly population shares in 2010.

\begin{tabular}{|c|c|c|c|c|}
\hline \multirow[t]{2}{*}{ Anatomical Therapeutic Chemical Classification (ATC) } & \multicolumn{4}{|c|}{ Prescribing Frequency: \% of Scheme Total in 2010} \\
\hline & GMS & DP & LTI & Total \\
\hline Alimentary Tract and Metabolism Total (of which) & 13.64 & 11.99 & 26.44 & $13.9 \%$ \\
\hline 1. Drugs for Acid related Disorders & 6.02 & 6.6 & 0.68 & \\
\hline 2. Drugs for Diabetes & 2.35 & 0.51 & 24.2 & \\
\hline 3. Laxatives & 1.4 & 0.67 & 0.26 & \\
\hline 4. Mineral Supplements & 1.93 & 2.01 & 0.24 & \\
\hline Cardiovascular System Total (of which) & 24.03 & 27.01 & 30.88 & $24.6 \%$ \\
\hline 5.Lipid Modifying Agents & 6.47 & 9.56 & 11.19 & \\
\hline 6.Renin-Angiotensin Agents & 5.85 & 7.27 & 10.68 & \\
\hline 7.Calcium Channel Blockers & 2.52 & 2.51 & 2.92 & \\
\hline 8. Beta Blocking Agents & 3.74 & 4.08 & 3.27 & \\
\hline 9. Diuretics & 3.11 & 1.81 & 1.51 & \\
\hline Nervous System Total (of which) & 19.44 & 15.47 & 10.52 & $18.4 \%$ \\
\hline 10. Psychoanaleptics & 4.59 & 4.64 & 0.55 & \\
\hline 11. Psycholeptics & 6.85 & 5.16 & 0.67 & \\
\hline 12. Anti-epileptics & 1.98 & 1.57 & 7.9 & \\
\hline 13. Analgesics & 4.76 & 3.42 & 0.26 & \\
\hline Respiratory System (of which) & 7.47 & 9.55 & 0.47 & $7.5 \%$ \\
\hline 14. Drugs for Obstructive Airways & 5.4 & 6.78 & 0.32 & \\
\hline 15. Nasal Preparations & 0.65 & 1.3 & 0.05 & \\
\hline 16. Antihistomines & 0.75 & 1.11 & 0.05 & \\
\hline Various Total (of which) & 3.02 & 1.98 & 17.64 & $3.5 \%$ \\
\hline 17. Clinical Nutritional Products & 1.1 & 0.96 & 1.26 & \\
\hline 18. Other Non-Therapeutic Products & 1.04 & 0.82 & 6.26 & \\
\hline 19. Diagnostic Products & 0.83 & 0.17 & 10.11 & \\
\hline Other Total (of which) & 32.4 & 34.00 & 14.05 & $31.9 \%$ \\
\hline 20. Antithrombotics & 6.9 & 6.86 & 9.72 & \\
\hline 21. Urologicals & 1.7 & 1.85 & 1.03 & \\
\hline 22. Antibacterials for Systemic Use & 4.64 & 4.2 & 0.52 & \\
\hline 23. Drugs for Bone Disease & 1.43 & 1.6 & 0.08 & \\
\hline 24. Anti-inflammatory and Rheumatic & 3.18 & 4.05 & 0.15 & \\
\hline Therapeutic Groups as a \% of Total Prescribed Items & $79 \%$ & $80 \%$ & $94 \%$ & $79.7 \%$ \\
\hline Total Prescribing Frequency for listed Therapeutic Groups & $43,127,161$ & $8,813,726$ & $2,638,371$ & $54,579,258$ \\
\hline Total Items Prescribed for all (inc. unlisted) therapeutic groups & $54,424,660$ & $11,070,446$ & $2,807,757$ & $68,302,863$ \\
\hline Persons Covered & $1,615,809$ & $2,841,218$ & 134,926 & $4,591,953$ \\
\hline Items prescribed per Person Covered & 33.68 & 3.90 & 20.81 & 14.87 \\
\hline
\end{tabular}

Tables 20/ 20.1/20.2 Primary Care Reimbursement Service (PCRS) 2010. Available at; http://www.hse.ie/eng/staff/PCRS/PCRS_Publications/claimsandpayments2010.pdf Table 3: Prescribing frequencies by anatomical group, listed therapeutic group and drug scheme. 


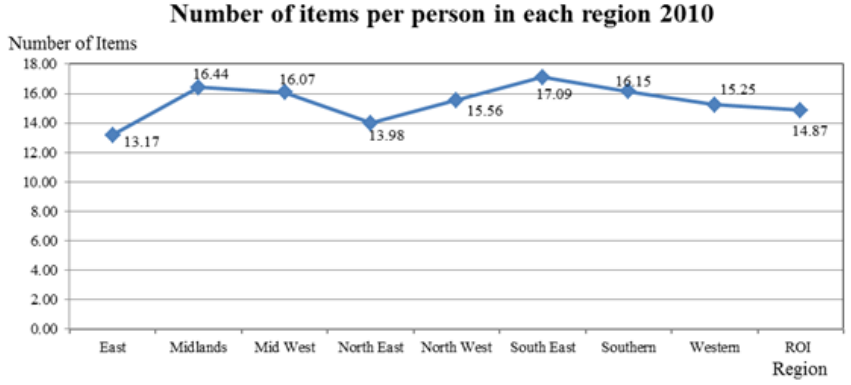

Figure 1: Considerable regional variation.

to obtain 24 regional EPRs in total - one for each of the 3 community drug schemes in each of the 8 regions.

The Midlands GMS average prescribing rate or APR is the actual number of GMS items prescribed in the Midlands region divided by its' GMS population. We computed APRs similarly for the DP and LTI drug schemes and repeated the exercise for the remaining 7 regions to obtain 24 regional APRs - one for each of the 3 community drug schemes in each of the 8 regions.

Coverage rates for community drug schemes vary widely from region to region, as detailed in Table 4 . For example, just $28 \%$ of the East region population was GMS-eligible in 2010 compared to a coverage rate of $49 \%$ in the North-West region. Accordingly, we weighted region $r^{\prime} s$, expected prescribing rate for drug scheme $j$ (i.e., $E P R_{r, j}$ ) by the share of the region $r$ population covered by scheme $j$, that is, by its coverage rate $s_{r, j}$. We then summed over the 3 schemes to obtain region $r^{\prime} s$ total expected prescribing rate $E P R_{r}$. Formally,

$$
E P R_{r}=\sum_{j=1}^{3} s_{r, j} * E P R_{r, j}=\sum_{i=1}^{6}\left[s_{r, G M S} * N P R_{i}^{G M S}+s_{r, D P} * N P R_{i}^{D P}+s_{r, L T I} * N P R_{i}^{L T I}\right] * I_{i}^{r}
$$

Where (i) $N P R_{i}^{j}$ is the national prescribing rate or norm for category $i$ ATC drugs under scheme $j$ (ii) $s_{r, j}$ is the coverage rate of scheme $j$ in region $r$ and (iii) $I_{i}^{r}$ is region $r^{\prime} s$ ATC category $i$ health index value. Scheme coverage rates in each region sum to one as those not covered by the GMD and LTI schemes are automatically eligible and covered by the DP scheme; hence $s_{r, G M S}+s_{r, D P}+s_{r, L T I}=1$.

Multiplying region $r^{\prime} s E P R_{r}$ by its population, $P O P_{r}$ and summing over the 8 regions gives the expected total number of community drug items prescribed in Ireland, $N$,

$$
N=\sum_{r=1}^{8} E P R_{r} * P O P_{r}
$$

Equation (1) allows us to analytically separate and simulate the effect on expected regional prescribing rates of changes in national prescribing norms, scheme coverage rates, and regional health status. Equation (2), allows us calculate the effects the same variables have on the expected total number of community drug items prescribed in Ireland $(N)$.

From (1), if the GMS national prescribing rates fall by $1 \%$, so that, $\triangle N P R_{i}^{\text {GMS }}=0.01 * N P R_{i}^{\text {GMS }}$ then,

$$
\triangle E P R_{r}=-\sum_{i=1}^{6}\left[N P R_{i}^{G M S}\right] * s_{r, G M S} * I_{r} * 0.01
$$

Whereas, if the GMS coverage rate increases (and DP coverage rate falls) by a percentage point then,

$$
\triangle E P R_{r}=\sum_{i=1}^{6}\left[\left(N P R_{i}^{G M S}-N P R_{i}^{D P}\right)\right] * I_{r} * 0.01
$$

The ratio of the right-hand sides of equations $3 \mathrm{a}$ and $3 \mathrm{~b}$ measures the impact national prescribing norms have, relative to GMS coverage rates, on regional prescribing rates and it simplifies to,

$$
s_{r, G M S} * \sum_{i=1}^{6} N P R_{i}^{G M S} / \sum_{i=1}^{6}\left[N P R_{i}^{G M S}-N P R_{i}^{D P}\right]=s_{r, G M S}(33.68 / 29.72)=1.133 * s_{r, G M S}
$$

Since all Irish regions have GMS coverage rates less than $88 \%$, a $1 \%$ change in national prescribing rates have a smaller impact on regional prescribing rates than a percentage point change in their GMS coverage rates. Moreover, the smaller the region's GMS coverage rate is the less effective national prescribing norms become, relative to its GMS coverage rate, in changing its regional prescribing rate.

Equation $3 c$ expresses the sensitivity of regional prescribing rates to national prescribing norms, relative to their sensitivity to GMS coverage rates as $1.133 * s_{r, G M S}$. The North-West $49 \%$ GMS coverage rate $\left(s_{N W, G M S}=0.49\right)$ allows us to infer that a $1 \%$ fall in GMS national prescribing rates had a little over half (56\%) the effect on that region's prescribing rate as a $1 \%$ increase in its GMS coverage rate. The East region GMS coverage rate was $28 \%\left(s_{E A S T, G M S}=0.28\right)$; if GMS coverage increased to $29 \%$ the East region prescribing rate response would be 3 times its response to a $1 \%$ fall in GMS national prescribing rates.

We regressed APR on EPR by OLS, using Microfit and used the regression $\mathrm{R}^{2}$ to assess the precision of the model; that is, how well the EPR model fits the APR data.

$$
A P R_{r}^{j}=\alpha+\beta E P R_{r}^{j}+u_{r}^{j}
$$

(Where $u_{r}^{j}$ is a well behaved stochastic error)

Moreover, if $\alpha=0$ and $\beta=1$ then each region's expected prescribing rate under each scheme, $E P R_{r}^{j}$ is an unbiased estimator of its actual prescribing rate, $A P R_{r}^{j}$.

We then augmented the core regression model - equation (4) with intercept dummy variables to test for scheme and region specific prescribing effects and deleted all dummy variables that were not significant at the $5 \%$ level.

Finally, we constructed scheme-independent EPRs for each region $r$ from the product of (i) the national prescribing rate and (ii) region $r^{\prime} s$ health index value. Thus, region $r^{\prime} s$ scheme-independent cardiac EPR (i.e., $E P R_{c}^{r}=A P R_{c}^{n} * I_{c}^{r}$ ) is identical across all of the GMS, DP and LTI drugs schemes in region $r$ but it varies across regions due to their differing health status, $I_{i}^{r}$. We regressed the APRs on the scheme-independentEPRs to test if regional health status and national prescribing norms alone could account for regional prescribing variations, independently of scheme coverage rates.

\section{Results}

The regression results are summarised in Table 5. The estimated core regression model is;

$$
A P R_{r}^{j}=0.028+0.975 E P R_{r}^{j}
$$

The core scheme-dependent EPR model tracks regional APRs closely and explains $92 \%\left(R^{2}=0.9238\right)$ of the variation in regional per capita prescribing rates. Moreover, the intercept and slope coefficients are insignificantly different from zero and one, respectively, which implies that the scheme-dependent EPRs are unbiased estimators of regional APRs.

The estimated augmented core model includes intercept dummies 


\begin{tabular}{|c|c|c|c|c|c|}
\hline Region / Scheme Coverage Rates $S_{\mathrm{j}}$ & GMS & $\mathbf{D P}^{*}$ & LTI & HTD $^{* *}$ & Total \\
\hline 1. Eastern Area $+2.5 \%$ & $0.28[25.46]$ & 0.67 & 0.04 & 0.01 & 1.00 \\
\hline 2. Midlands & 0.38 & 0.58 & 0.03 & 0.01 & 1.00 \\
\hline 3. Mid-West & 0.38 & 0.59 & 0.02 & 0.01 & 1.00 \\
\hline 4. North-East & 0.38 & 0.58 & 0.03 & 0.01 & 1.00 \\
\hline 5. North-West $+2.14 \%$ & $0.49[46.86]$ & 0.47 & 0.03 & 0.01 & 1.00 \\
\hline 6. South-East & 0.41 & 0.55 & 0.03 & 0.01 & 1.00 \\
\hline 7. South & 0.36 & 0.61 & 0.02 & 0.01 & 1.00 \\
\hline 8. West & 0.41 & 0.56 & 0.02 & 0.01 & 1.00 \\
\hline Ireland & 0.35 & 0.61 & 0.03 & 0.01 & 1.00 \\
\hline \multicolumn{6}{|c|}{ National Prescribing Rates (NPRs): Items per person Covered by ATC Group and by Scheme in Ireland } \\
\hline 1. Alimentary Tract / Metabolism & 4.59 & 0.48 & 5.50 & 0.03 & 2.07 \\
\hline 2. Cardiovascular System & 8.09 & 1.07 & 6.42 & 0.09 & 3.69 \\
\hline 3. Central Nervous System & 6.55 & 0.61 & 2.19 & 0.04 & 2.74 \\
\hline 4. Respiratory System & 2.52 & 0.38 & 0.10 & 0.08 & 1.12 \\
\hline 5. Various & 1.02 & 0.08 & 3.67 & 0.02 & 0.51 \\
\hline 6. Other & 10.91 & 1.35 & 2.93 & 6.88 & 4.83 \\
\hline Total & 33.68 & 3.96 & 20.81 & 7.14 & 14.96 \\
\hline
\end{tabular}

*Persons not covered by the GMS are covered by the DP scheme. We assigned covered but unregistered persons (i.e. those with medicines bills under $€ 120$ / month entitlement threshold) to the DP scheme. ${ }^{* *}$ We assigned the 54,974 HTD registered persons in 2010 (PCRS 2010 p.14) to each region in proportion to that region's share of HDT items prescribed (PCRS 2010 p.15). Source PCRS http://www.hse.ie/eng/staff/PCRS/PCRS_Publications/claimsandpayments2010.pdf

Table 4: Drug scheme coverage rates by region and national prescribing rates in 2010.

for the North West region GMS scheme and the South region LTI scheme. Model fit increased to $R^{2}=0.9735$ and both dummy variables are significant at the $5 \%$ level.

$$
A P R_{r}^{j}=0.042+1.009 E P R_{r}^{j}-8.562 N W_{G M S}+11.543 S_{L T I}
$$

The augmented model implies that, given its health status, scheme coverage rates and national prescribing norms, the North-West region GMS prescribing rate was significantly less - by nearly 9 items per GMS-eligible person - than expected, whereas the South region LTI prescribing rate of 32.67 items per eligible LTI person was almost 12 items more than the expected rate of 20.89 items. With these two exceptions EPRs are unbiased and precise estimators of APRs for each scheme and region.

Model fit collapsed when APRs were regressed on the schemeindependent EPRs (Table 5).This confirms that health status and national prescribing norms alone cannot explain prescribing rates. Community drug scheme coverage rates exert powerful intermediating effects on prescribing frequency that cannot be purged when calculating EPRs without serious misspecification and catastrophic loss of explanatory power.

Regional prescribing depends on regional health status, regional drug scheme coverage rates and national prescribing norms. Using equations 1 and 2 we simulated how much community drug prescribing in Ireland responds to (i) a uniform percentage point gain in each region's health status and (ii) a uniform percentage point reduction in each region's GMS coverage rate (with a corresponding increase in its DP coverage rate).

A percentage point gain in health status in each ATC category and region would reduce community drug prescriptions in Ireland by around 680,000 items. Table 6gives the breakdown by region and ATC therapeutic drug group. The populous East region shows the largest regional reduction: prescriptions of "Other" drugs and Cardiovascular ATC category drugs fall most. "Other" drugs include bone disease and anti-thrombotic drugs; see [11] for a full listing.

In contrast, reducing the GMS population in each region uniformly by a percentage point (and giving automatic DP cover to those who lose GMS cover) reduces community drug prescriptions by approximately 1,350,000 items (see Table 6).

Whereas regions with higher GMS coverage rates clearly tend to have higher regional prescribing rates, ironically, the same is not always true at national level: in 2008, 2009 and 2010 as the national GMS coverage rate was increasing to $31.89 \%, 34.87 \%$ and $38.11 \%$, respectively, the national GMS prescribing rate was falling to 35.65 , 34.3 and 33.68 items per GMS person covered, respectively. This apparent paradox was due to the introduction of nominal GMS prescription charges in January 2009 (which had been free until then), the withdrawal of GMS coverage for some high income elderly persons and increased patient co-payment rates for the entire DP population. These fiscal measures reduced GMS national prescribing rates while simultaneously preserving the pattern of higher regional prescribing rates in those regions that had higher GMS coverage rates.

In the boom period preceding recession GMS and LTI prescriptions grew faster than DP prescriptions and GMS items moderated more slowly during the slump (Table 7). In the boom-dominated decade to 2010 GMS items grew by $112 \%$, LTI items by $142 \%$ and DP items by just 23\%. Between 2009 and 2010, as austerity measures took effect, DP items fell by $17 \%$, LTI items fell by $2 \%$ and GMS items continued to increase but at the moderated rate of 7\%: as recession also increased the GMS population by $9 \%$, GMS national prescribing rates per person or norms fell by $2 \%$. By 2010 the national GMS drugs basket had 33.68 


\begin{tabular}{|c|c|c|c|c|c|c|}
\hline \multirow{2}{*}{$\begin{array}{c}\text { Dependent Variable is } A P R_{r}^{j} \\
\text { Regressor }\end{array}$} & \multicolumn{2}{|c|}{ Scheme Dependent EPR Model } & \multicolumn{2}{|c|}{$\begin{array}{c}\text { Augmented Scheme Dependent EPR } \\
\text { Model }\end{array}$} & \multicolumn{2}{|c|}{ Scheme Independent EPR Model } \\
\hline & Coefficient & T-Stat & Coefficient & T-Stat & Coefficient & T-Stat \\
\hline Intercept & +0.828 & $+0.5971^{*}$ & +0.0419 & $+0.0526^{*}$ & +10.508 & $+0.3114^{*}$ \\
\hline EPR & +0.9755 & $+16.34^{* *}$ & +1.009 & $+28.56^{* *}$ & +0.6099 & $+0.28331^{*}$ \\
\hline DNW $_{\text {GMS }}$ & & & -8.562 & $-3.939^{* *}$ & & \\
\hline DS $_{\text {LTI }}$ & & & +11.5434 & $+5.5136^{* *}$ & & \\
\hline $\mathbf{R}^{2}$ & \multicolumn{2}{|c|}{0.9238} & \multicolumn{2}{|c|}{0.9743} & \multicolumn{2}{|c|}{0.06029} \\
\hline F-Stat & \multicolumn{2}{|c|}{267.01} & \multicolumn{2}{|c|}{292.2} & \multicolumn{2}{|c|}{0.0802} \\
\hline
\end{tabular}

$\mathrm{DNW}_{\mathrm{GMS}}=1$ if the North-West GMS APR rate; zero otherwise. DS $\mathrm{LTI}_{1}=1$ if the South LTI APR rate; zero otherwise. *Insignificant at the $5 \%$ level ** Significant at the $1 \%$ level. Table 5: OLS Regression results for scheme dependent, augmented and scheme independent models.

\begin{tabular}{|c|c|c|c|c|c|c|c|c|}
\hline $\begin{array}{c}\text { Region/ ATC } \\
\text { Category of } \\
\text { Prescription Item }\end{array}$ & Alimentary & Cardiovascular & $\begin{array}{l}\text { Central } \\
\text { Nervous } \\
\text { System }\end{array}$ & Respiratory & Various & Other & TOTAL & $\begin{array}{c}1 \% \text { Fall in GMS } \\
\text { Coverage Rate } \\
\text { and } 1 \% \text { Gain in } \\
\text { DP rate. }\end{array}$ \\
\hline East & 29,664 & 52,656 & 37,812 & 15,612 & 7,912 & 66,086 & 209,741 & 453,706 \\
\hline North-West & 6,751 & 11,932 & 9,129 & 3,624 & 1,646 & 15,540 & 48,622 & 79,693 \\
\hline Midlands & 6,037 & 10,750 & 8,051 & 3,264 & 1,491 & 13,875 & 43,467 & 87,889 \\
\hline South-East & 11,541 & 20,505 & 15,473 & 6,231 & 2,833 & 26,556 & 83,139 & 151,320 \\
\hline Mid-West & 8,188 & 14,659 & 11,024 & 4,491 & 1,974 & 19,027 & 59,363 & 113,437 \\
\hline South & 13,354 & 24,148 & 18,208 & 7,504 & 3,096 & 31,577 & 97,887 & 193,806 \\
\hline North-East & 9,297 & 16,606 & 12,480 & 5,071 & 2,260 & 21,518 & 67,233 & 123,188 \\
\hline West & 10,083 & 18,085 & 13,772 & 5,588 & 2,360 & 23,686 & 73,575 & 135,414 \\
\hline IRELAND & 94,915 & 169,341 & 125,950 & 51,386 & 23,572 & 217,865 & 683,028 & $1,351,182$ \\
\hline
\end{tabular}

Table 6: Simulated prescribed items fall from (a) a $1 \%$ gain is health status (b) a $1 \%$ fall in GMS coverage.

\begin{tabular}{|c|c|c|c|}
\hline Year / Scheme & GMS & DP & LTI \\
\hline \multicolumn{4}{|c|}{ Prescribed Items } \\
\hline 2010 & $54,424,660$ & $11,070,446$ & $2,807,757$ \\
\hline 2009 & $50,721,919$ & $13,372,525$ & $2,855,361$ \\
\hline 2005 & $37,561,068$ & $10,581,689$ & $1,929,111$ \\
\hline 2001 & $25,658,179$ & $8,985,466$ & $1,157,876$ \\
\hline \multicolumn{4}{|c|}{ Prescribed Items Growth Rates } \\
\hline 1 Year Growth Rate: 2009 / 2010 & $+7 \%$ & $-17 \%$ & $-2 \%$ \\
\hline 5 Year Growth Rate: 2005 / 2010 & $+45 \%$ & $+5 \%$ & $+46 \%$ \\
\hline 9 Year Growth Rate: 2001 / 2010 & $112 \%$ & $23 \%$ & $142 \%$ \\
\hline
\end{tabular}

* Source. Primary Care Reimbursement Services Database. Available for 2010, 2009 and 2005 at http://www.hse.ie/eng/staff/PCRS/PCRS_Publications/ claimsandpayments2010.pdf and for 2001 at http://www.hse.ie/eng/Staff/PCRS/PCRS_Publications/GMS_Payments_Board_Annual_Report_2001.pdf

Table 7: Total community drug scheme prescribed items and growth rates (2001-2010).

items per person covered; the LTI basket had 20.81 items and DP basket had just 3.9 items (Table 3 ).

Figures 2.1, 2.2 and 2.3 use Table 8 data to plot the composition by ATC category of the GMS, DP and LTI drugs baskets in 2005, 2009 and 2010. The GMS and DP Drug baskets reflect the health profiles of their respective large populations and are broadly similar in composition; LTI basket is distinctive. Our model predicts the total regional prescribing rates and also regional prescribing rates by ATC category. However, we await a PCRS published breakdown of prescribed items by region, drug scheme and ATC category. Besides up-scaling the sample size 6-fold that would enable detailed testing of how well the model fits regional prescribing patterns in each ATC category. For example, how closely tied are regional Nervous System prescribing rates and regional Nervous System health status and, similarly, how much the lower and falling share of cardiovascular items in the GMS basket vis-à-vis its higher and growing share in the DP basket reflect differences in the evolution of cardiovascular health in both populations, nationally and regionally.

\section{Discussion and Conclusion}

Naughton et al. [12] previously related regional prescribing rates to elderly persons in Ireland to the regional prevalence rates for chronic disease. We extended this by covering all primary care community drug prescriptions to all persons in Ireland, broken down by region and by the six ATC therapeutic drug groups. Our model closely tracks prescribing rates under the three community drug schemes and in the eight health regions of Ireland and it quantifies their dependence on community drug scheme coverage rates, national prescribing norms and health status. We find that regional prescribing rates tend to be higher in regions with poor health status. Moreover, regional prescribing rates also respond more to changes in national prescribing norms or to changes in GMS coverage rates in regions that have poorer health status. For example, controlling for other factors, the cardiac prescribing rate is $15 \%$ higher in the Midlands and $8 \%$ lower in the East region than nationally; formally, $I_{C}^{M I D}=1.15$ and $I_{C}^{E A S T}=0.92$ in equation 1. Total prescribed items is the product of the prescribing rate and population (equation 2) hence the same gain in health status reduces total prescribed items more in the East region, with $36 \%$ of 
Page 7 of 8

\begin{tabular}{|c|c|c|c|c|}
\hline \multirow[b]{2}{*}{ GMS DRUGS BASKET: ATC COMPOSITION } & \multicolumn{4}{|c|}{ Percentage of all GMS Prescribed Items } \\
\hline & 2010 & 2009 & 2005 & 2001 \\
\hline Alimentary Tract and Metabolism & 13.64 & 13.45 & 12.25 & 10.92 \\
\hline Cardiovascular System & 24.03 & 24.29 & 24.97 & 22.28 \\
\hline Nervous System & 19.44 & 19 & 19.17 & 21.09 \\
\hline Respiratory & 7.47 & 7.39 & 7.31 & 8.63 \\
\hline Various & 3.02 & 3.49 & 2.92 & 2.43 \\
\hline Other & 32.4 & 32.38 & 33.38 & 34.65 \\
\hline \multirow[t]{2}{*}{ Total } & 100 & 100 & 100 & 100 \\
\hline & \multicolumn{4}{|c|}{ Percentage of all DP Prescribed Items } \\
\hline DP DRUGS BASKET: ATC COMPOSITION & 2010 & 2009 & 2005 & 2001 \\
\hline Alimentary Tract and Metabolism & 11.99 & 11.66 & 10.89 & 10.38 \\
\hline Cardiovascular System & 27.01 & 26.94 & 25.36 & 23.15 \\
\hline Nervous System & 15.47 & 14.97 & 15.05 & 17 \\
\hline Respiratory & 9.55 & 9.58 & 10.27 & 11.37 \\
\hline Various & 1.98 & 1.75 & 1.77 & 1.87 \\
\hline Other & 34.0 & 35.1 & 36.66 & 36.23 \\
\hline \multirow[t]{2}{*}{ Total } & 100 & 100 & 100 & 100 \\
\hline & \multicolumn{4}{|c|}{ Percentage of all LTI Prescribed Items } \\
\hline LTI DRUGS BASKET: ATC COMPOSITION & 2010 & 2009 & 2005 & 2003 \\
\hline Alimentary Tract and Metabolism & 26.44 & 25.93 & 26.59 & 28.37 \\
\hline Cardiovascular System & 30.88 & 29.83 & 26.37 & 21.68 \\
\hline Nervous System & 10.52 & 10.82 & 13.11 & 15.95 \\
\hline Respiratory & 0.47 & 0.56 & 0.71 & 0.9 \\
\hline Various & 17.64 & 17.82 & 19.51 & 22.19 \\
\hline Other & 14.05 & 15.04 & 13.71 & 10.91 \\
\hline Total & 100 & 100 & 100 & 100 \\
\hline
\end{tabular}

Source: Primary Care Reimbursement Service. Statistical Analysis of Claims and Payments. Various Issues. Available at: http://www.hse.ie/eng/staff/PCRS/PCRS Publications/claimsandpayments

Table 8: Drug Basket ATC composition by community drug scheme: Various years.

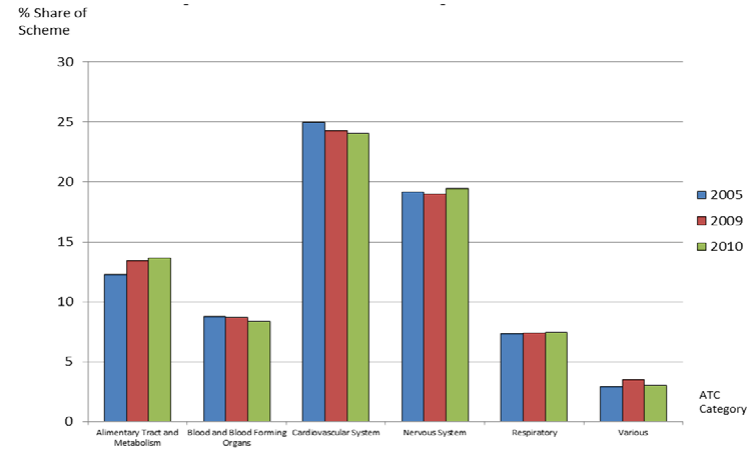

Figure 2.1: General medical services: Drug Basket 2005, 2009, 2010

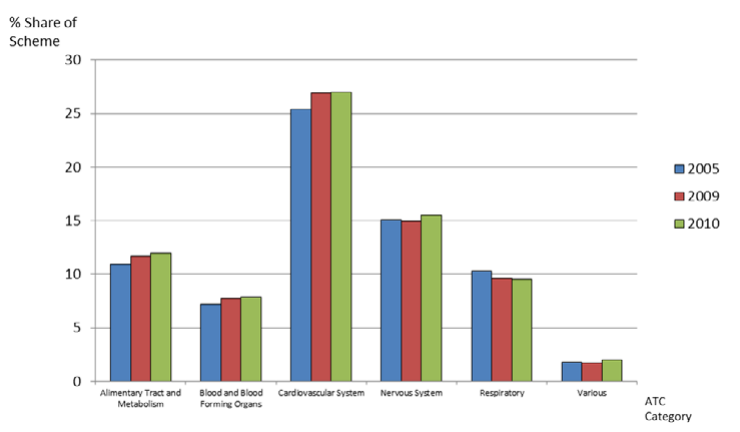

Figure 2.2: Drug payment: Drug Basket 2005, 2009, 2010.

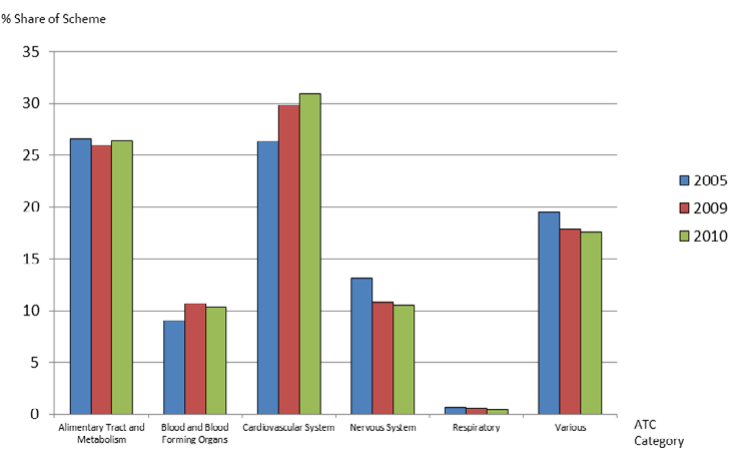

Figure 2.3: Long term illness: Drug Basket 2005, 2009, 2010.

Ireland's population, than in the Midlands with just 6\%.

GMS coverage provides near free access to primary care and medicines and the resulting 2010 GMS drugs basket was 1.6 times the LTI basket and 9 times the DP basket. These drug baskets had been larger, peaking in 2008 before moderating in 2009 and 2010, in response to the measures adopted to restrain public drug costs during Ireland's fiscal crisis: a GMS prescription charge of $€ 0.50$ per item were first introduced in January 2009, GMS eligibility conditions for over 70 s were tightened and DP co-payment rates were increased.

Our simulations show that total national prescribing frequency responds twice as elastically - by $1.35 \mathrm{~m}$ items or $2.48 \%$ - when GMS coverage rates are increased by a percentage point compared to 0.68 
$\mathrm{m}$ items or $1.24 \%$ if health status improves by a percentage point: they fall $1 \%$ if all national prescribing norms fall by a percentage point. As Ireland's fiscal crisis deepened between 2008 and 2010 its policy horizon shortened, cost containment took centre stage and government focussed on restraining the growing number of drug baskets and their average size.

And as the cost containment measures it adopted pressured national prescribing rates down, regional prescribing rates fell most in those regions that had high GMS coverage rates, low income and poor health status. For example, the North-West had the highest GMS coverage rate (49\%) in 2010 and the East region had the lowest (28\%). This elevated the North-West region's prescribing response rate to a change in national prescribing norms to around 1.75 times (i.e., 49 / 28) that of the East region (see equation 3a) and to twice that of the East region when its poorer health status is also factored in with $I^{N W}=1.06$ and $I^{E A S T}=0.94$, respectively, in equation $3 \mathrm{a}$.

Consequently, when the fiscal measures adopted reduced GMS national prescribing norms by $2 \%$ in 2010 they reduced the East region prescribing rate by 0.17 items per person but the North-West rate by 0.34 items per person. Recession increased the GMS coverage rate by $2.5 \%$ in the East region and by $2 \%$ in the North-West region In 2010, which increased their respective prescribing rates similarly by 0.698 items and by 0.63 items per person, respectively (see equation $3 b$ ). The combined outcome of both the reduced GMS national prescribing norms and increased GMS coverage rates was that prescribing increased by 0.528 items per person in the East region but by just 0.29 items per person in the North-West. The policy implication is striking: prescribing increased more in the younger, higher-income, Dublincentred East region population than in the older, lower income, remote and scattered North-West region population. In fact, as inspection of equation (1) shows, cuts in GMS prescribing norms reduced the East region prescribing rate less than in any other region, because it had the lowest initial GMS coverage rate, $s_{r, G M S}$. The corollary is that falling national GMS prescribing norms had their greatest prescribing rate impacts on regions with high GMS coverage rates, which were generally the poorer, less healthy, outlying regions.

The cost containment measures government adopted were not regionally neutral and ironically they flout the second of four high level goals government later set out in its 2013 Healthy Ireland policy document [13], which is to reduce health inequalities and gaps between the wealthiest and most deprived areas.

National prescribing norms that wax and wane with the economic tide can scarcely promote population health. Prescribing guidelines, for example, for antibiotics and benzodiazepines [14,15] do not generally vary with the economic cycle: newer drug therapies tend to grow secularly rather than cyclically, for example, the use of statins in treating and reducing CHD mortality rates [16] and lower vaccination and immunization rates lower present prescribing rates but at the expense of future ill-health and higher future prescribing rates.

Pro-cyclical fiscal policy in Ireland spawned pro-cyclical prescribing rates and 'put the drugs cart before the medical horse'. Government could better promote public health by structurally balancing its budgets and spending counter-cyclically to ensure it has sufficient 'rainy day' funds to safeguard the primacy of health need and medical expertise in setting prescribing rates and avoid magnifying regional health inequalities and inducing the un-assayed health consequences of procyclical prescribing rates.

The North-West and Donegal region has a lower than expected
GMS prescribing rate, which may relate to its remote location and sparsely distributed population. The South region has a higher than expected LTI prescribing rate. Both of these exceptions are significant and sizeable and they warrant separate investigation of their causes and health consequences.

\section{References}

1. McCarthy Colm (2009) Report of the Special Group on Public Service Numbers and Expenditure Programmes. Government Publications Office, Molesworth Street Dublin.

2. Central Statistics Office (2015) System of Health Accounts. Ireland's System of Health Accounts: Annual Results 2013.

3. Health Service Executive (2013) National Service Plan

4. Walshe V, Kenneally M (2013) Community drug expenditure and recent cost containment measures. Ir Med J 106: 44-46.

5. Gorecki PK, Nolan A, Brick A, Lyons S (2012) Delivery of Pharmaceuticals in Ireland: Getting a Bigger Bang for the buck. Economic and Social Research Institute (ESRI), Policy Research Series, ESRI, Dublin.

6. OECD: OECD Health Statistics (2013).

7. Primary Care Reimbursement Service (2010) Statistical Analysis of Claims and Payments.

8. Barry M, Malloy D, Usher C, Tilson L (2009) Drug Expenditure in Ireland. Irish Medical Journal 102: 106.

9. Walsh V, Kenneally M, Buckley G (2013) Variances in Individual Prescription Drug Costs in Ireland ISPOR (International Society for Pharmaceutical Outcomes Research) International Conference.

10. World Health Organization (WHO) (2016) Collaborating Centre for Drugs Statistics Methodology.

11. Kenneally M, Lynch B (2013) Variations in the Health Status of Irish Regions Dublin ISPOR Conference Presentation Dublin Nov 4-6. Centre for Policy Studies Working Paper CPS-WP:14 UCC.

12. Naughton C, Bennett K, Feeley J (2006) Regional variation in prescribing for chronic conditions among an elderly population using a pharmacy claims database. Irish Journal of Medical Science 175: 32-39.

13. Health Services Executive (HSE) (2013) Healthy Ireland.

14. Health Services Executive (HSE) (2016) Guidelines for Antimicrobial Prescribing in Primary Care in Ireland.

15. Department of Health and Children (2002) Benzodiazepines: good practice guidelines for clinicians. Department of Health and Children Dublin.

16. Kabir Z, Perry IJ, Critchley J, O'Flaherty M, Capewell S, et al. (2013) Modeling Coronary Heart Disease Mortality declines in the Republic of Ireland, 19852006 Int J Cardiol 168: 2462-2467. 